\title{
CHEMICALLY AMPLIFIED IMAGING MATERIALS BASED ON ACID-CATALYZED REACTIONS OF POLYESTERS OR ELECTROPHILIC CROSSLINKING PROCESSES.
}

\author{
J.M.J. Frechet", B. Kryczka ${ }^{a}$, S. Matuszczak, B. Reck ${ }^{b}$, M. Stanciulescu ${ }^{\text {c }}$, C.G. Willson ${ }^{\text {b }}$.
}

Department of Chemistry, Baker Laboratory, Cornell University,

Ithaca, New York, 14853 1301, U.S.A.

The design of chemically amplified imaging systems based on acid catalyzed thermolytic cleavage of polymer main-chains has been exploited with a variety of structures containing tertiary, allylic, or benzylic ester groups. In all cases, the esters have been designed for their ability to undergo facile thermolytic elimination. This report outlines the preparation, study, and imaging of several polyesters containing thermolytically active moieties. These new acid labile polyesters have been incorporated into two-component imaging materials for which radiation sensitivity is due to the presence of compounds which produce acid upon irradiation. The photogenerated acid is then used to catalyze thermolytic cleavage of the polyester main-chain in a process which does not consume the acid and therefore provides for chemical amplification. Imaging is possible using a variety of radiation sources, from deep-UV to $x$-rays. The concept of imaging through multiple main-chain cleavage is important as it can lead to self- or dry developing images. In the present study, only partial self-development was observed as one of the diacid liberated by the chain cleavage process was not volatile. A second family of radiation sensitive imaging materials has also been designed based on the catalyzed electrophilic crosslinking of polymers containing aromatic rings. While this new approach is only illustrated here for systems in which crosslinking involves polymer pendant groups, the same design is also applicable to polymer main-chains. This family of crosslinkable, chemically amplified, resist materials shows very high sensitivities of ca. $1 \mathrm{~mJ} / \mathrm{cm}^{2}$ for exposure in the deep-UV, ca. $1 \mu \mathrm{c} / \mathrm{cm}^{2}$ for E-beam exposure, and ca. $12-15 \mathrm{~mJ} / \mathrm{cm}^{2}$ for $\mathrm{x}$-ray synchrotron radiation.

${ }^{a}$ University of Lódz, Institute of Organic Chemistry, Lódz, Poland.

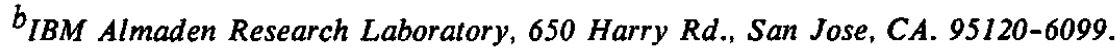

${ }^{c}$ University of Ottawa, Department of Chemistry, Ottawa, Ontario, Canada KIN-9B4. 


\section{Introduction}

Early work on deep-UV resist designs incorporating chemical amplification was carried out in 1979 when Fréchet and willson [1, 2] first prepared poly ( $p-t$-butyloxycarbonyloxystyrene) and photoactive derivatives of poly (phthalaldehyde). Poly(t-Boc-styrene) [3] was designed for its ability to lose its phenolic $t-B O C$ protecting group under a variety of conditions thereby liberating a polymer of vastly different solubility - poly(4-hydroxystyrene) - for which aqueous base development would be possible. In contrast, the design of the polyacetals based on the phthalaldehyde building block [2] hinged on a ceiling temperature phenomenon whereby photochemical cleavage of the polymer main-chain would result in depolymerization of the entire polymer chain in a process which amounts to self-development. This basic approach to chemical amplification was later brought to full fruition by Ito et al. [4] with the introduction of triaryl sulfonium salts in the resist formulation. Photolysis of the onium salt results in the formation of acid within the polymer matrix and facilitates the transformation or depolymerization process which leads to ultimate image formation.

While the conceptual design of the poly (phthalaldehyde) based resist materials is useful, the polymers themselves had too great a tendency to depolymerize to be of practical value in the current context of resist imaging. In contrast, more stable yet readily depolymerized systems became available as the catalyzed thermolysis process which characterizes the chemistry of the poly(t-BOC-styrene) resists was applied to main-chain polycarbonates $[5,6]$.

We have recently used similar concepts for the design of poly (formals) [7] and polyesters that can undergo acid catalyzed depolymerization processes to afford small molecules [8]. other studies extending our original work on polymers with pendant $t-B O C$ groups have also appeared $[9,10]$.

\section{Design and synthesis of Depolymerizable Polyesters}

The thermolysis of esters is a well known reaction [11] which has been reviewed by Taylor [12]. For simple esters the reaction is facile if the ester has a beta hydrogen; it proceeds through a six-centered six electron cyclic transition state as shown in scheme $I$ below.

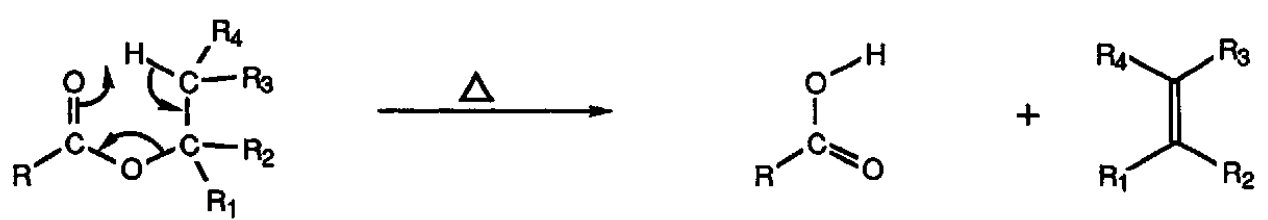

\section{Scheme I}

In general, the reaction is greatly affected by the polarity of the transition state and therefore the pyrolysis of tertiary esters occurs at a much 
lower temperature than is the case for secondary or primary esters. In addition, our previous work with the thermolysis of polycarbonates $[5,6]$ has shown that allylic and benzylic moieties also require lower temperatures for the elimination to occur.

of particular importance in the context of this study is the fact this thermolysis reaction is catalyzed by acid as shown in scheme II below. Again the acid-catalyzed thermolysis reaction will be most readily achieved with appropriate tertiary, allylic, or benzylic esters that contain beta hydrogens. In practical terms, this means that in the presence of an acid, the temperature at which the thermolysis will occur for a given ester will be reduced sharply. Though the exact lowering in thermolysis temperature will depend on the type of ester structure involved as well as on exact reaction conditions, it will frequently be observed that under acid catalysis this lowering may amount to $100^{\circ} \mathrm{C}$ or more.<smiles>[R]C(=O)OC([R7])([R])C([R6])[2H]</smiles>
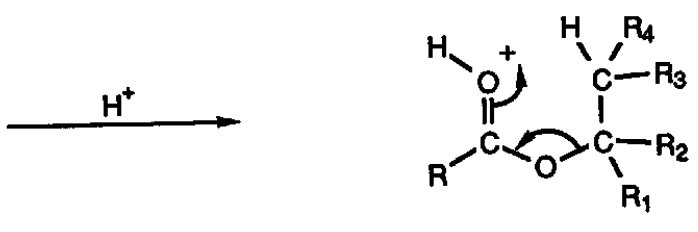

Scheme II<smiles>[R]C([R])=C([R])[18OH]</smiles><smiles>CC(C)C(=O)O</smiles>

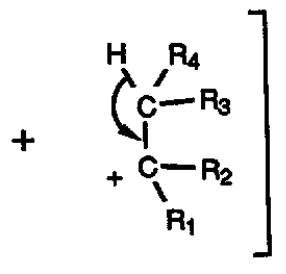

The mechanism which is outlined in Scheme II clearly shows the origin of chemical amplification for resist or imaging materials based on catalyzed thermolysis of polymers. While the overall process is initiated by a proton, which in our case will be produced photochemically in situ, the elimination reaction proceeds with liberation of another proton, thereby ensuring that the process may continue without requiring another photochemical event.

The synthesis of thermally labile polyesters presents a significant challenge as polyesters are routinely obtained through high temperature polycondensation reactions. As this route is not appropriate for our purpose, we have studied several alternate procedures with the help of model compounds. An interesting approach which proved successful, is based on the work of staab [13] who described esterification reactions using 1,1'-carbonyl-dilmidazole to activate the carboxylic acid. In our modification of this approach (Scheme III), the bis-acylimidazole derivative of isophthalic acid, $\underline{1}$, is prepared either by reaction of isophthaloyl chloride with imidazole, or by reaction of the free diacid with 1,1'-carbonyl-diimidazole. 

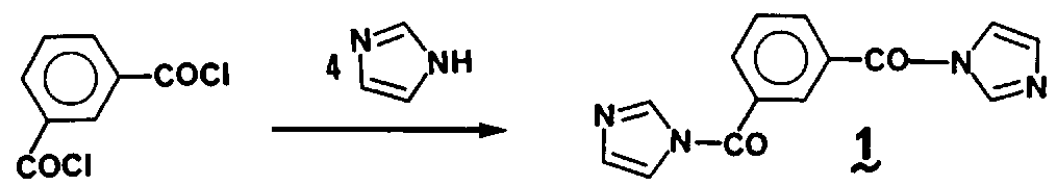

\section{Scheme III}

Compound $\mathbf{1}$, or its para substituted analog $\underline{\mathbf{2}}$, can then be condensed with diol $\underline{3}$ using a trace of sodium [13] or iodomethane [14] as the catalyst for the polyesterification process (Scheme IV). As can be seen in Scheme IV, a large variety of diols, 3a-i, have been tested in this polycondensation and details for all of these reactions will appear elsewhere [15]. All of these polyesters, with the notable exception of $\mathbf{4 f}$ which is derived from benzenedimethanol, have structural features which allow for their facile thermolytic breakdown as they possess the beta protons that are needed for the elimination reaction to occur. of all these structures, $1 \mathrm{~A}$ and $\mathbf{f b}$ are the most promising in terms of their suitability for imaging materials. In general, the polyterephthalates $\underline{5}$ have insufficient solubility in the solvents that might be used for spin-coating and are therfore less useful than the meta substituted polyesters.

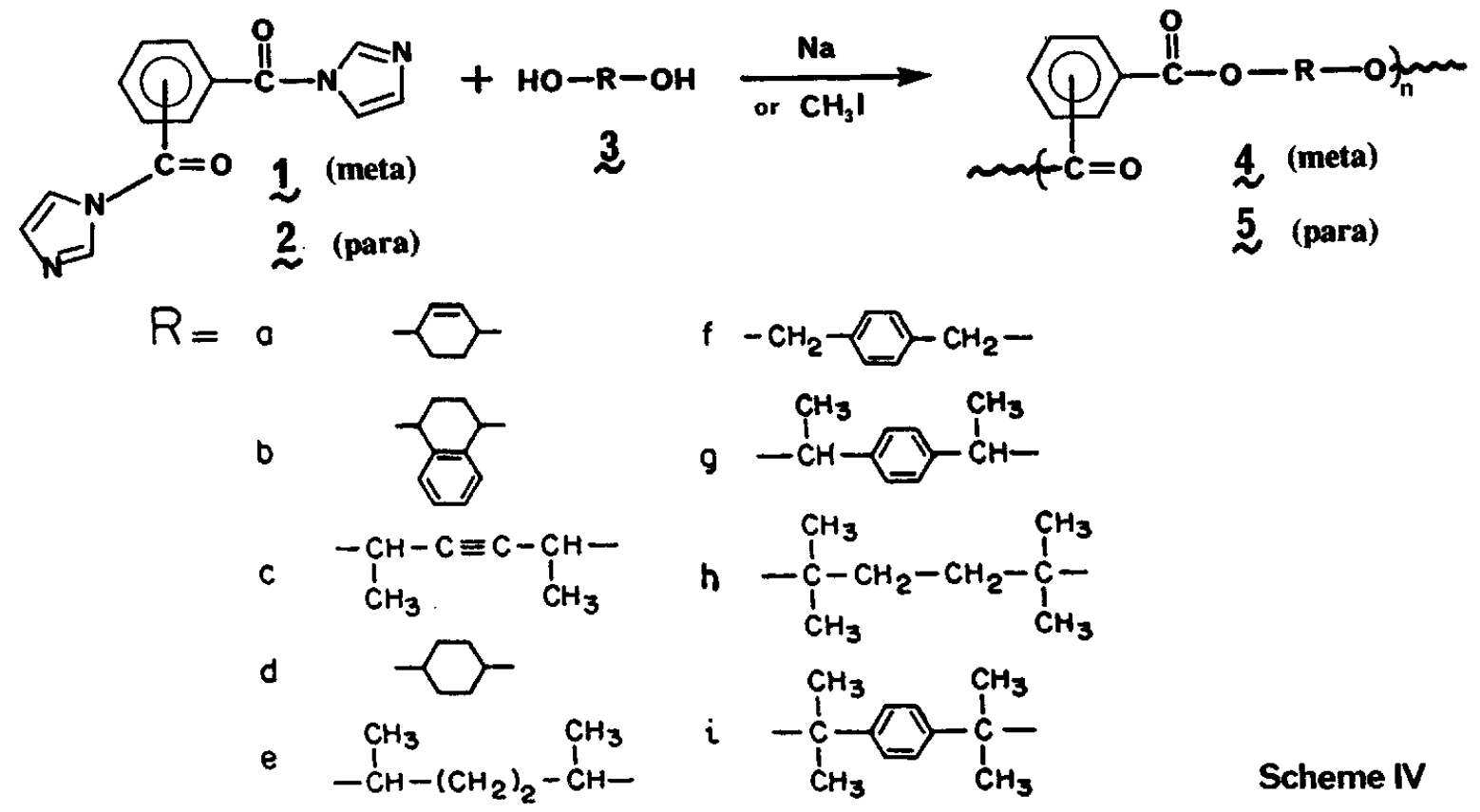

An alternate route for the preparation of polyesters such as 4 a involves a nucleophilic displacement of bromide from 3,6-dibromo-cyclohex-1-ene using the diacid under phase transfer conditions in the presence of solid potassium carbonate and 18-crown-6.

\section{Thermolysis of the Polyesters}

The thermolysis of the polyesters was studied as a model for the imaging reactions. While several different polyesters were studied, only the data 
concerning polymer 4 a will be presented here. The thermogravimetric behavior of $4 a$ is shown in Figure 1. As can be seen in this Figure, the polymer decomposes cleanly leaving essentially no residue $\left(0.6 \%\right.$ and $0.25 \%$ remaining mass at $420^{\circ} \mathrm{C}$ in duplicate experiments). The decomposition process starts as expected near $240^{\circ} \mathrm{C}$, with a high rate of decomposition observed near $265^{\circ} \mathrm{C}$. This temperature

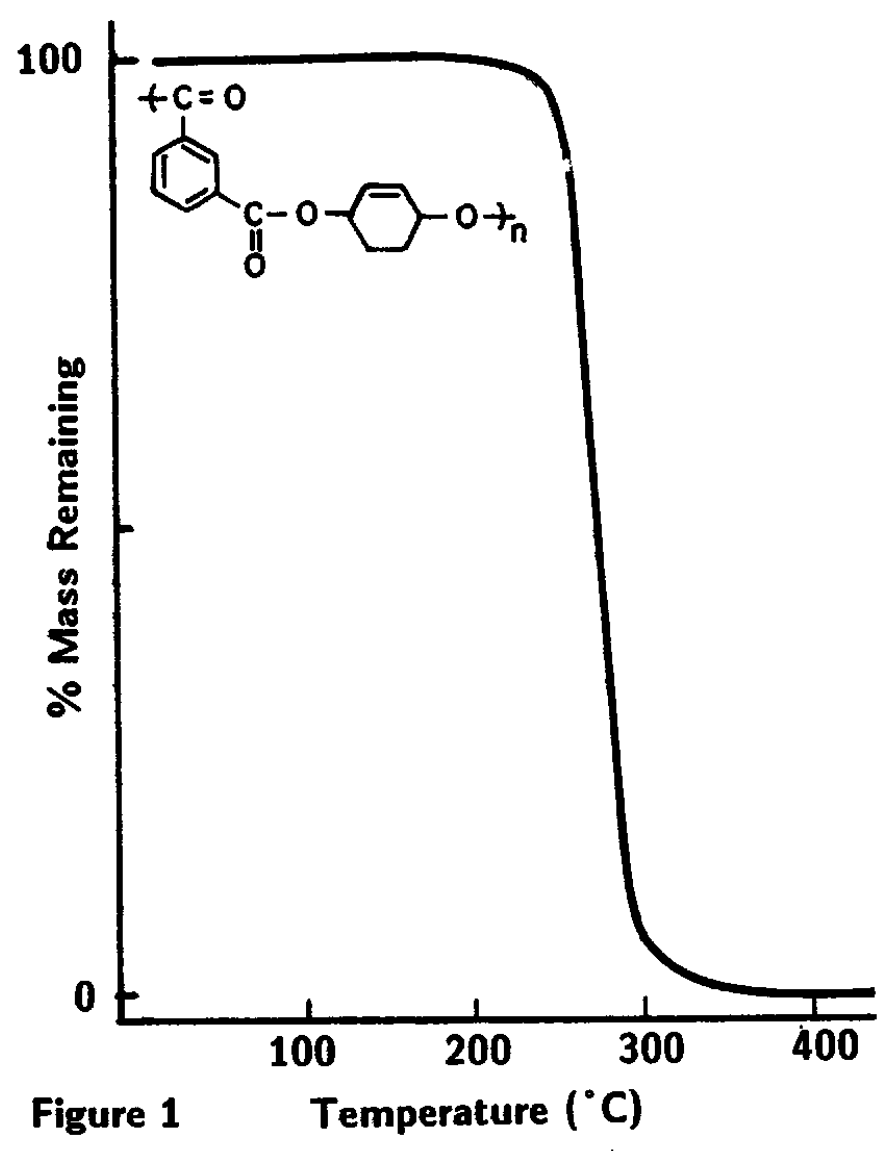
is approximately $20^{\circ} \mathrm{C}$ higher than that observed $[5 \mathrm{c}, 6,16]$ for somewhat analogous polycarbonates derived from the same diol $\underline{3 a}$ in agreement with our observation of the higher thermal lability of the polycarbonates when compared to polyesters due to the additional electronic effect found in the carbonate structure. The decomposition process was also monitored by thermolysis-mass spectrometry as well as by experiments involving a combination of thermolysis, gas chromatography (with derivatization of the diacid liberated) and mass spectrometry. The products of the decomposition were found to be isophthalic acid and benzene, with small amounts of 5-hydroxy-1,3-cyclohexadiene being also detected. The diene originates from the thermal decomposition of the chain ends of the polyester.

Imaging of the Polyesters.

As was the case for other imaging materials using the catalyzed thermolysis design [1-10], the formulation of the imaging material is based on a twocomponent system including the polyesters and a substance which produces acid upon irradiation. While most of our work has involved the use of triarylsulfonium salts as acid photogenerators, there are also a number of other substances which are available for the same purpose [17, 18]. As was pointed out above for scheme II, the advantage of this imaging process is that a single photogenerated proton may actually cause the cleavage of a very large number of ester bonds. Recent studies have suggested that in such chemically amplified systems effective quantum yields of the order of $10^{3}$ can be achieved [19].

The imaging process used with polyester $4 \mathrm{a}$ is shown in scheme $\mathrm{V} \cdot 1 \mu \mathrm{m}$ thick films of polymer 4 a containing 5 wts triphenylsulfonium hexafluoroantimonate were coated onto $5^{\prime \prime}$ silicon wafers, baked, and exposed through a 


\section{IRRADIATION}

Scheme V

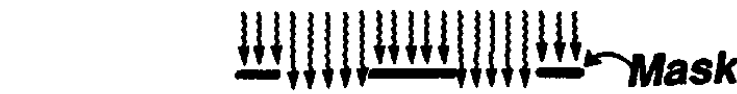
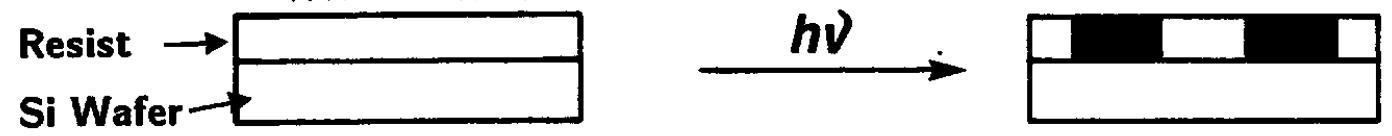

Latent Image
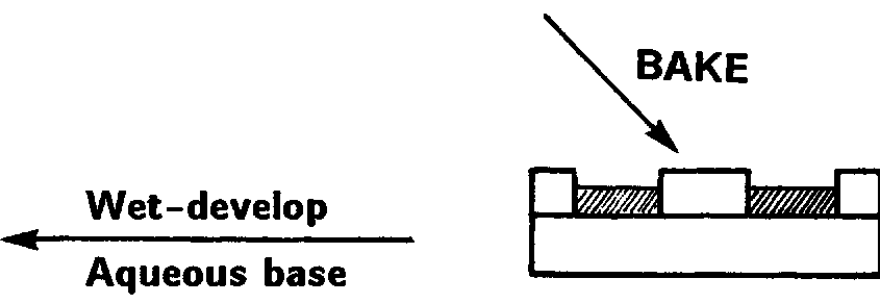

Positive-tone image

Partial dry Development

mask using a Perkin-Elmer 500 projection printer (at 254nm). Following a brief post-exposure bake near $100^{\circ} \mathrm{C}$, a positive tone, partially dry-developed, relief image is clearly seen. While a significant reduction in film thickness is observed in the exposed areas of the film, a solid residue of isophthalic acid remains. This residue is easily removed by dipping the wafer in aqueous base. A similar technique was used to image some of the other polyesters. Minor adjustments were made with the post-bake temperatures (from 70 to $100^{\circ} \mathrm{C}$ ) and the developing solvent depending on the exact structure of the polymer. Sensitivities were generally reasonably high, with doses ranging from 6 to $14 \mathrm{~mJ} / \mathrm{cm}^{2}$ (filtered $254 \mathrm{~nm}$ light) being applied to produce images such as those presented in Figure 2 .
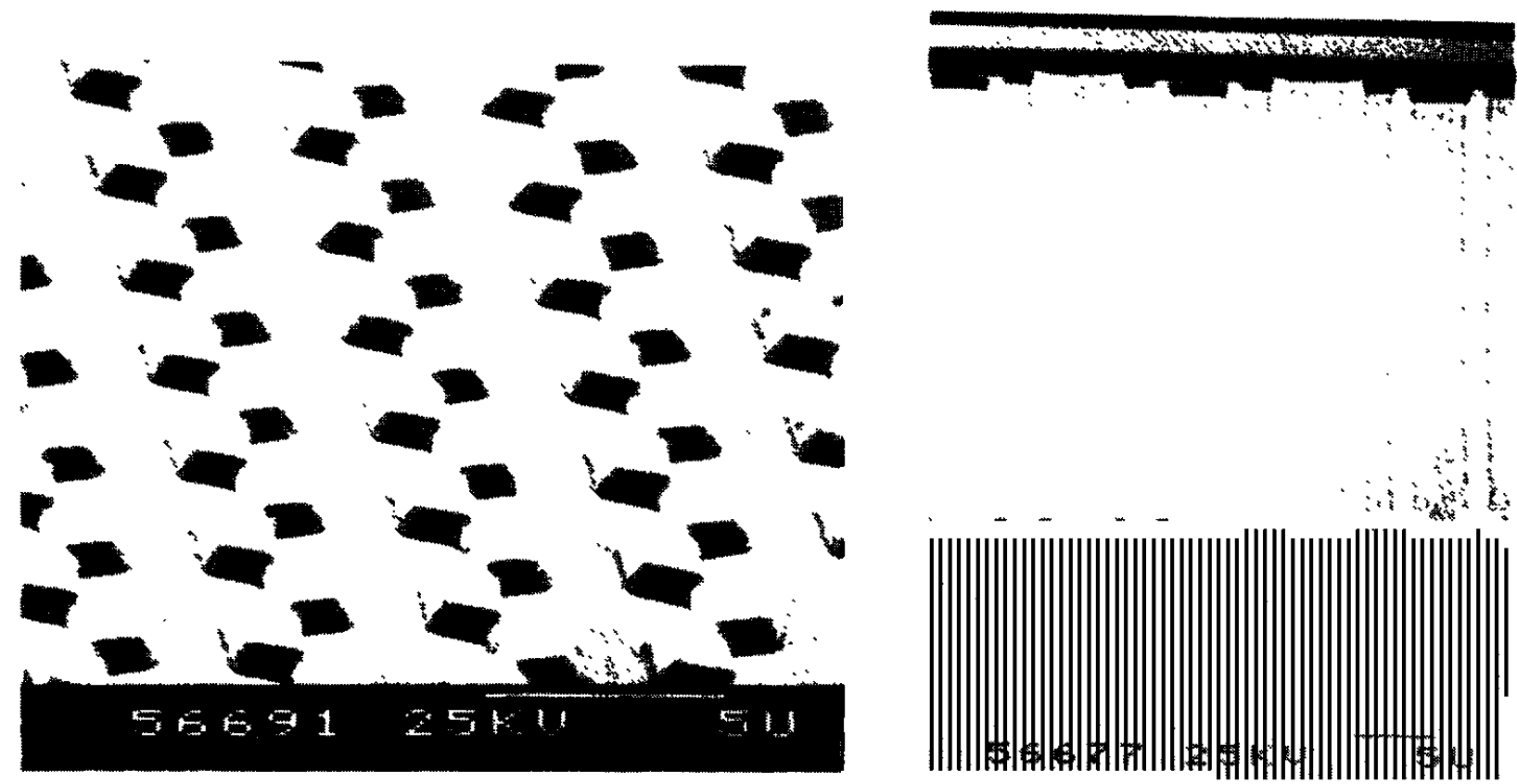

Figure 2. Positive-tone images obtained with the polyester resist containing $5 \%$ triphenyl sulfonium salt. 
Design of Negative Resists Based on Electrophilic Aromatic substitution

While much of our previous work had focused on the design of imaging systems based on the catalyzed thermolysis of polycarbonates, polyethers, or polyesters, the following describes a new resist design based on electrophilic aromatic substitution. The first implementation of this approach involves a system for which imaging will result from radiation-induced crosslinking of a polymer matrix. In order to preserve the high throughput which is required for state-of-the-art applications, the design will incorporate chemical amplification.

A comparison of the processes required for imaging classical positive-tone and negative-tone resists reveals significant differences which have a direct effect on design strategies for high sensitivity and high resolution materials. For a classical Novolac-diazonaphthoquinone positive resist, satisfactory images are only obtained when a significant proportion of the diazonaphthoquinone dissolution inhibitor has been transformed into the corresponding indenecarboxylic acid photoproduct, a process which is not normally prone to chemical amplification. In the case of our newer generation of dual-tone resists such as the [poly(t-Boc-styrene) - photoacid generator] system [1-4] or analogs [18-20], the requirements for imaging are different. Imaging is obtained via a change in polymer side-chain polarity, an approach which also requires that a relatively large number of reactive groups in the polymer be transformed by the radiationinduced imaging process [2]. However, two factors contribute to the very high sensitivity of materials based on this design: the first is related to the very high efficiency of the thermolysis reaction that is used to modify the polymer side-chains, the second is derived from the catalytic nature of the deprotection reaction. In this instance, radiation is only used to produce a catalytic amount of acid within the exposed areas of the polymer coating, this acid can then effect numerous successive side-chain modification reactions, and therefore chemical amplification is observed providing more than an order of magnitude increase in sensitivity when compared to classical positive resists. In contrast, even in the absence of chemical amplification, high sensitivity is much more readily achieved with a resist system that operates on the basis of radiation induced crosslinking since only a very small number of crosslinking events are required to insolubilize the polymer chains. obviously, chemically amplified processes would result in even higher sensitivities being achieved. The remaining consideration is that of resolution. This is more problematic with crosslinking resists due to the swelling which is usually observed during development of crosslinked images. A very interesting and imaginative approach to the control of swelling was introduced by Iwayanagi et al. in 1981 [21]. In this approach, a phenolic resin is used in combination with a bis-azide photocrosslinker. Negative image development is possible without significant swelling since removal of the unexposed areas of the resist involve an ionization, or chemical etching, of the phenolic resin (transformed into the corresponding 
phenolate), rather than a simple dissolution process.

our approach to highly sensitive high resolution negative-tone resists will therefore involve both chemically amplified processes and crosslinkable materials based on phenolic resins. The process of electrophilic aromatic substitution shown below (Scheme VI) is responsible for the achievement of chemical amplification.

1) $\phi_{3} \mathrm{~s}^{+} \mathrm{SbF}_{6}^{-} \stackrel{\mathrm{hv}}{\longrightarrow} \mathrm{H}^{+}$

\section{Scheme VI}

2)

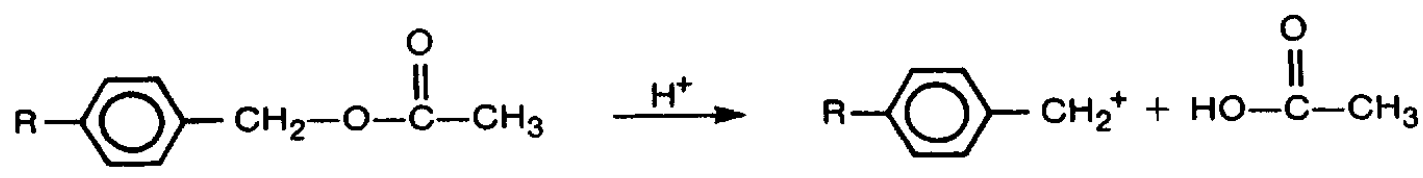

3)
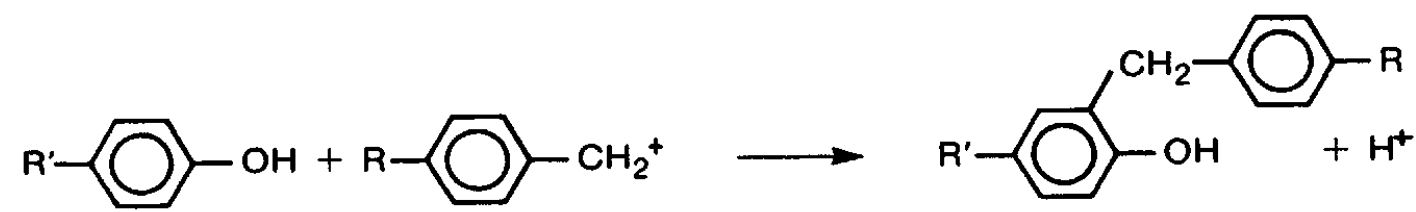

The reaction sequence which is used can be summarized as follows: In the first step acid is generated by photolysis of a triaryl sulfonium salt. Subsequent reaction with a latent electrophile, such as a substituted benzyl acetate, produces a carbocationic intermediate while acetic acid is liberated. The carbocationic intermediate then reacts with neighboring aromatic moieties in a coupling reaction which also liberates a proton; this ensures that the overall process is catalytic and results in chemical amplification.

Our first implementation of this reaction scheme involved the preparation of a series of copolymers $Z$ incorporating both a latent électrophile and an electron-rich aromatic moiety in different proportions. The presence of phenolic groups in polymer $\underline{Z}$ also provides access to swelling-free development in aqueous medium. Precursor copolymers 6 containing varying proportions of the two functionalities (latent electrophile and activated aromatic) are prepared by copolymerization of 4-t-butyloxy-carbonyloxy-styrene with 4-acetoxymethylstyrene.<smiles>CCCc1ccc(OC(=O)OC(C)(C)C)cc1</smiles> 
Although the reactivity ratios of these two monomers are different [22] they copolymerize essentially in random fashion. Removal of the t-Boc protecting groups from precursor copolymers $\underline{6}$ is best done by refluxing in glacial acetic acid (Scheme VII), a process which does not affect the acetoxymethyl pendant groups or the molecular weigh distribution of the final copolymers $\underline{Z}$.

Imagewise exposure of films of the various copolymers containing from $5-10 \%$ triphenylsulfonium hexafluoroantimonate to $\mathrm{UV}$ light at $254 \mathrm{~nm}$ results in the crosslinking of the exposed areas as shown in Scheme VIII below. In the first step, irradiation of selected areas of the polymer film causes the formation of a latent image consisting of protons dispersed in the matrix copolymer. This is followed by baking to $100^{\circ} \mathrm{C}$ to provide the activation energy necessary for the electrophilic process to occur with crosslinking of the exposed areas of the film. As was shown in scheme VI, each electrophilic aromatic substitution step is accompanied by liberation of a proton, therefore the acid that had been photogenerated initially is not consumed and a single proton may ultimately be responsible for the formation of a large number of crosslinks. The final step of the imaging process is the development of the unexposed areas of the polymer film using aqueous base.

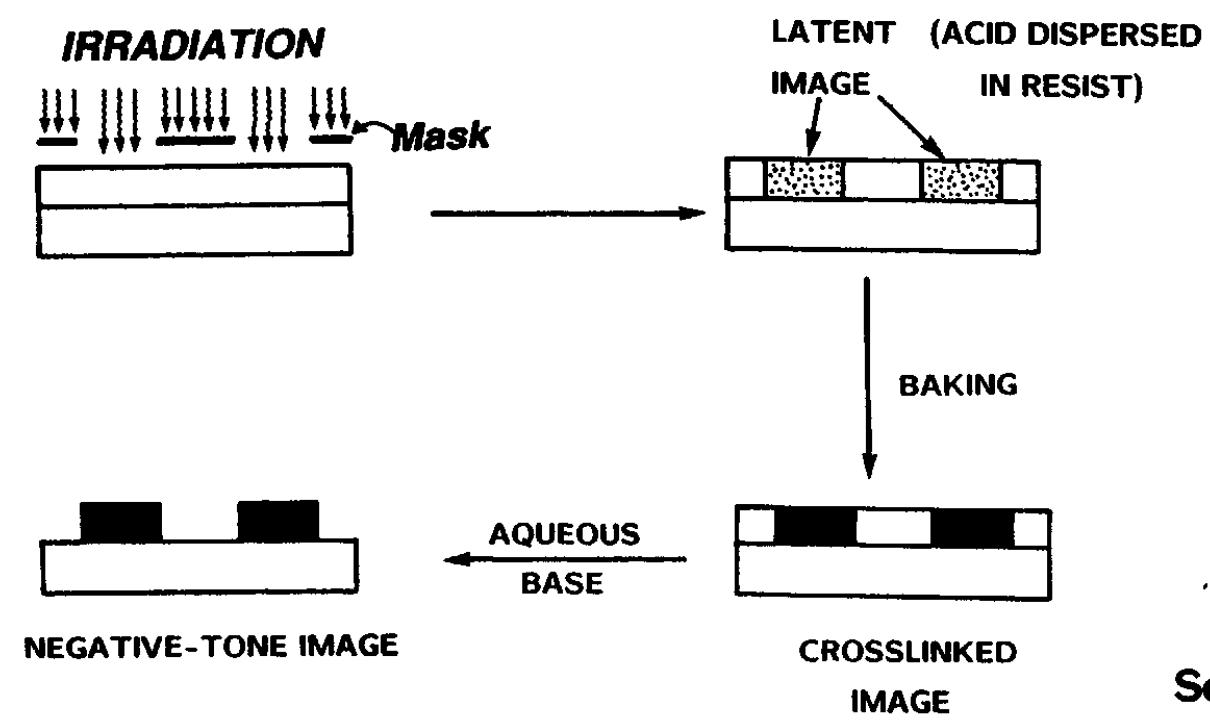

The characteristic curve [23] of a typical copolymer containing $80 \%$ of phenolic and $20 \%$ of benzylic acetate units together with $10 \%$ of triphenylsulfonium hexafluoroantimonate was determined using $1 \mu \mathrm{m}$ thick films and exposure to varying doses of $254 \mathrm{~nm}$ radiation through a narrow bandwidth $\mathrm{Hg}-\mathrm{line}$ filter. The characteristic curve shows the thickness of the insolubilized regions of the film remaining after development as a function of $\log$ (exposure dose). These measurements provide access to $\mathrm{D}_{\mathrm{g}}^{i}$ or gel dose, the minimum dose required to observe the formation of an insoluble residue, as well as $D_{g}^{\circ}$ the minimum dose required to produce an insolubilized film of thickness equal to that of the starting film ( $1 \mu \mathrm{m}$ in this instance). As can be seen in Figure 3, the lithographic sensitivity of the $80 / 20$ copolymer containing $10 \%$ onium salt is 
approximately $1 \mathrm{~mJ} / \mathrm{cm}^{2}$ while its contrast (slope of the curve) is higher than 5 . other copolymer compositions show similar sensitivities though it must be emphasized here that the sensitivity of any such material depends on a variety of factors including the percentage and nature of the photoacid generator, the molecular weight of the copolymer being used, and the processing and development conditions. For a 50/50 copolymer the lithographic sensitivity is approximately $0.6 \mathrm{~mJ} / \mathrm{cm}^{2}$ with a very high contrast of over 14 . In these sensitivity experiments the $80 / 20$ copolymer was easily developed in aqueous base (dilute AZ2401) developer, while development of the 50/50 copolymer required that some isopropanol be used in combination with the AZ-2401 developer.

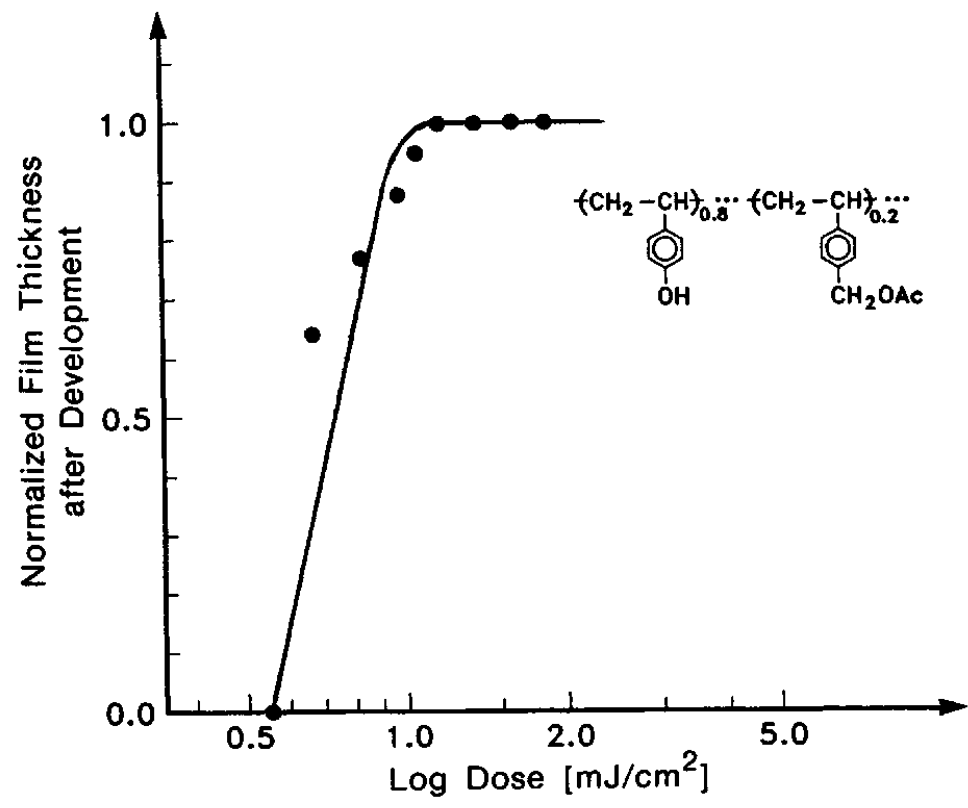

Figure 3. Characteristic curve for 80:20 copolymer containing $10 \%$ onium salt. Deep-UV exposure (254 nm)

A somewhat similar concept involving a crosslinkable phenolic polymers is based on the use of a multicomponent systems that incorporates polyfunctional low molecular weight crosslinkers. For example, we have described the use of polymers containing hydroxystyrene moieties in combination with polyfunctional latent crosslinkers [24], while Feely et al. [25] have used hydroxymethyl melamine in combination with a photoactive diazonaphthoquinone to crosslink a novolac resin.

Imaging of Resists Based on Electrophilic Aromatic substitution

A typical resist formulation involved the use of 95 wt: of the $80 / 20$ copolymer and 5 wts of the triphenylsulfonium hexafluoroantimonate in an appropriate solvent. After spin-coating onto silicon wafer to $1 \mu \mathrm{m}$ thickness and baking 5-15 min at $100-120^{\circ} \mathrm{C}$, the wafer was exposed through a mask to $<2 \mathrm{~mJ} / \mathrm{cm}^{2}$ of filtered $254 \mathrm{~nm}$ radiation (Perkin-Elmer 500 scanner), then post-baked $3 \mathrm{~min}$. at $100-125^{\circ} \mathrm{C}$, and developed using aqueous base developer (for example a $1: 1$ mixture of MF312 and water). Figure 4 shows a scanning electron micrograph of an image obtained after exposure of a $5^{\prime \prime}$ wafer to $254 \mathrm{~nm}$ filtered UV light 
(Perkin Elmer 500 scanner) and development in aqueous MF312 developer as discussed above.

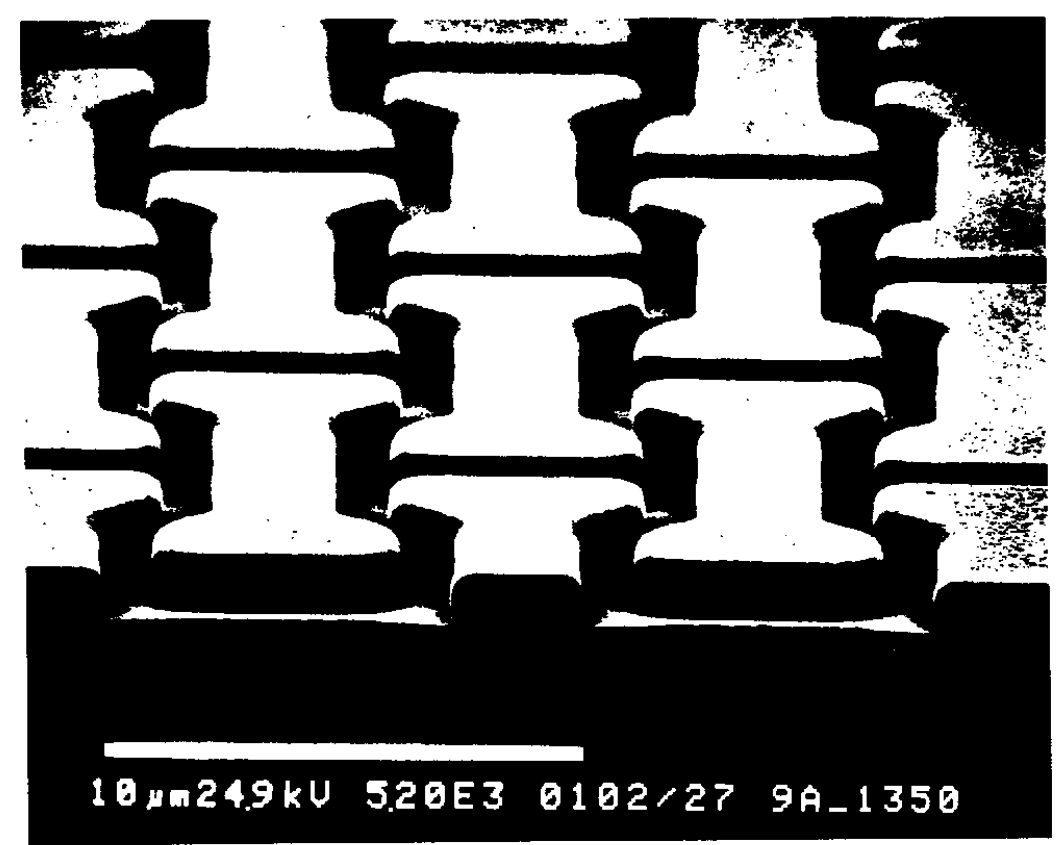

Figure 4. Negative-tone image obtained by deep-UV exposure $(254 \mathrm{~nm})$ using the $80 / 20$ copolymer.

Good results were also obtained using electron beam exposure with sensitivities of ca. 1-2 uc/ $\mathrm{cm}^{2}$ being obtained depending on the loading of photoacid generator. Similarly, the resist could be used with synchrotron $x-r a y$ exposure using doses of less than $20 \mathrm{~mJ} / \mathrm{cm}^{2}$ (Figure 5).

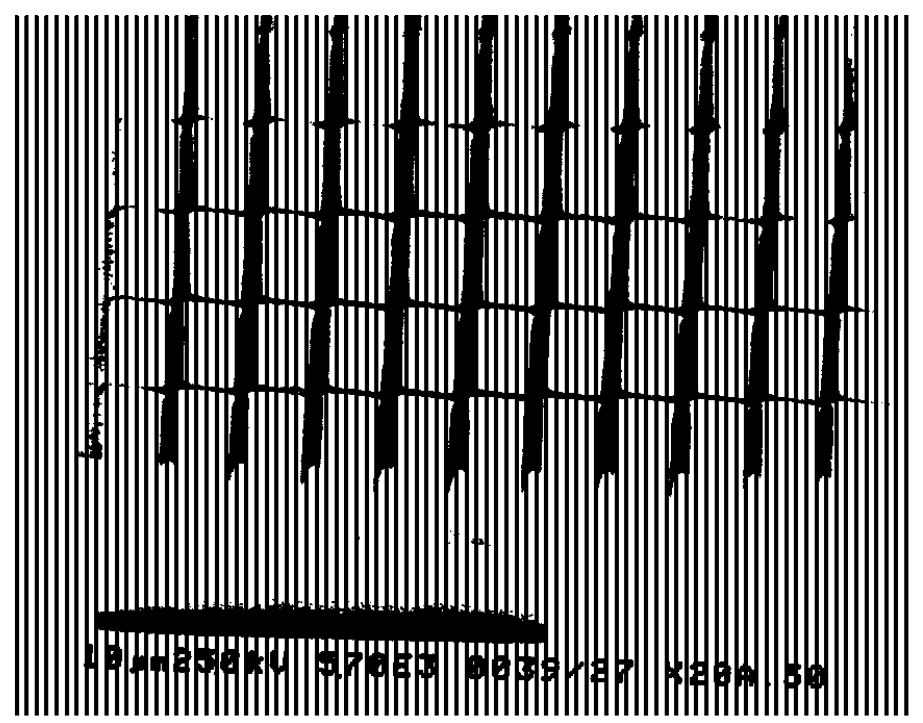

Figure 5. Negative-tone image obtained using the $80 / 20$ copolymer and Synchrotron $\mathrm{X}$-ray radiation. 


\section{Conclusion}

The design of chemical amplified imaging materials operating on the basis of acid-catalyzed processes is possible using a great variety of polymer structures. As was the case for polymers containing carbonate or ester functionalities, this work confirms that the acid-catalyzed thermolysis of esters is a valuable reaction for imaging materials. Processes involving multiple mainchain cleavages have the potential to lead to self- or dry-developing materials, but the polymers which are produced may not possess sufficient resistance to processing steps such as plasma etching to be of value as conventional resists. They are nevertheless of great potential interest in applications such as radiation-deformable materials, fugitive binders for high grade ceramics, or nonconventional imaging systems. other chemically amplified two-component systems such as the poly(t-Boc-styrene)-photoacid generator resist which operates on the basis of polymer side-chain deprotection are more suitable for applications in microlithography. Our new resists that operate on the basis of radiation-triggered electrophilic aromatic substitution processes also show great potential. They can be exposed using a variety of radiation sources and offer great sensitivities while maintaining high resolution. We are currently exploring the possibility of creating improved materials based on the same type of chemistry.

\section{Acknowledgements}

Financial support for this work was provided by IBM Corporation Materials and Processing Sciences Program and SUR Program. This support is gratefully acknowledged. Thanks are also due to $\mathrm{Mr}$. N. clecak for his gracious and invaluable help with imaging experiments.

\section{References}

1. J.M.J. Fréchet, H. Ito, C. G. Willson, : Sensitive Deep UV Resist Incorporating Chemical Amplification. Proceedings Microcircuit Engineering 1982, Grenoble, 260. C.G. Willson, H. Ito, J.M.J. Fréchet: Chemical Amplification in the Design of Polymers for Resist Application. Proceedings Microcircuit Engineering 1982, Grenoble, 251. C. G. Willson, H. Ito, J.M.J. Fréchet, F. Houlihan, Proc. IUPAC 28th Macromol. Symp., Amherst, Mass., 443 (1982). H. Ito, C. G. Willson, J.M.J. Fréchet, Proc. Tokyo Conf. VLSI, Tokyo, Japan (1982).

2. For a review of this and other early work on chemical amplification, see: C.G. Willson, H. Ito, J.M.J. Fréchet, T.G. Tessier, F.M. Houlihan, J. Electrochem. Soc., 133, 181 (1986)

3. J.M.J. Fréchet, E. Eichler, C. G. Willson, H. Ito; Polymer, 24,995 (1983).

4. H.Ito, C.G. Willson, J.M.J. Fréchet, U.S. Patent 4,491,628 (1985) 
5. F. M. Houlihan, F. Bouchard, J.M.J. Fréchet, C. G. Willson, Macromolecules 19, 13 (1986). J. M.J. Fréchet, A. Deratani, G. Darling, P. Lecavalier, N.H. Li; Makromol. Chem., Makromol. Symp. 1,91 (1986). J.M.J. Fréchet, F. Bouchard, F.M. Houlihan, E. Eichler, B. Kryczka, C. G. Willson, Die Makromol. Chem. Rapid Commun., 7, 121 (1986).

6. J.M.J. Fréchet, F. Bouchard, E. Eichler, F. M. Houlihan, T. Iizawa, B. Kryczka, C. G. Willson, Polymer Journal, 19, 31 (1987).

7. J.M.J. Fréchet, C. G. Willson, T. Iizawa, T. Igarashi, J. Fahey, ; ACS symposium series, \#412 "Polymers in Microlithography" [E. Reichmanis, S.A. MacDonald and T. Iwayanagi, Editors], (1989) 100.

8. J.M.J. Fréchet, M. Stanciulescu, T. Iizawa, C. G. Willson, Polym.Mat.sci.Eng.60, 170 (1989).

9. F.M. Houlihan, E. Reichmanis, L.F. Thompson, R.G. Tarascon, ACS Symposium Series \# 412 "Polymers in Microlithography", [E. Reichmanis, S.A. MacDonald and T. Iwayanagi, Editors], Chapter 3, 39, (1989).

10. Y. Jiang, J.M.J. Fréchet, C.G. Willson, Polymer Bulletin, 17, 1 (1987).

11. A. Oppenheim, H. Precht, Chem. Ber., 9, 325, 1876. C.D. Hurd, F.H. Blunck, J. Am. Chem. Soc., 60, 2419, 1938

12. R. Taylor, in Chemistry of Carboxylic acids and derivatives, (s.Patai Editor), Chapter 15, 859, Wiley, New York 1979.

13. H.A. Staab, Angew. Chem. Int. Ed., 1, 351, (1962).

14. T. Kamijo, H. Harada, K. Iizuka, Chem. Pharm. Bull., 32, 5044, 1984.

15 M. Stanciulescu and J.M.J. Fréchet, Manuscript in preparation.

16 F.T. Bouchard, M.Sc. Thesis, University of Ottawa, 1986.

17. G. Buhr, R. Dammel, C.R. Lindley, Polym. Mat. Sci. Eng., 61, 269 (1989).

18. F.M. Houlihan, A. Shugard, R. Gooden, E. Reichmanis, Macromolecules, 21, 2001 (1988). F.M. Houlihan, T.X. Neenan, E. Reichmanis, J.M. Kometani, I.F. Thompson, Polym. Mat. Sci. Eng., 61, 296 (1989)

19. D.R. MCKean, U. Shaedeli, S.A. MacDonald, ACs Symposium Series \#412 "Polymers in Microlithography" [E. Reichmanis, S.A. MacDonald and T. Iwayanagi, Editors], Chapter 2, 27 (1989).

20. J.V. Crivello, Polym. Mat. Sci. Eng., 61, 62 (1989). Ibid., 61, 422 (1989). D.A. Conlon, J.V. Crivello, J.L. Lee, M.J. o'Brien, Macromolecules, 22, 509 (1989).

21. T. Iwayanagi, T. Kohashi, S. Nonogaki, T. Matsuzawa, K. Douta, H. Yanazawa, IEEE Trans. Electr. Devices, ED-28, 1306 (1981).

22. S. Matusczak, J.M.J. Fréchet, Manuscript in preparation.

23. C.G. Willson, "Introduction to Microlithography", ACS Symp. Series \#219, Chapter 3, 87 (1983)

24. R.D. Allen, J.M.J. Fréchet, R.J. Twieg, C.G. Willson, Us Patent 4,800,152 (1989) .

25. W.E. Feely, Proc. SPIE, 631, 48 (1986). 